\title{
Déficit de proteína $C$ en un paciente con coagulación intravascular diseminada asociada a sepsis y trombosis venosa profunda
}

\author{
Protein $C$ deficiency in patient with sepsis-associated disseminated intravascular \\ coagulation and deep vein thrombosis. Case report
}

Dr. Mauro Tassin ${ }^{a}$, Dr. Pablo Llarena ${ }^{a}$, Dr. Federico Laffaye ${ }^{a}$ y Dr. Germán Kaltenbach ${ }^{a}$

\begin{abstract}
RESUMEN
La coagulación intravascular diseminada es un síndrome clinicopatológico que complica a varias enfermedades graves; la sepsis es la causa más común en los pacientes pediátricos. Resulta de una anormal activación del sistema de coagulación, que conduce a la formación de trombos en la microcirculación, y al consumo de plaquetas y factores de la coagulación. Los hallazgos clínicos son variables; las hemorragias son la presentación más frecuente, seguidas de la púrpura y la gangrena de las extremidades (púrpura fulminante).

Se presenta el caso de un paciente con coagulación intravascular diseminada asociada a sepsis, con trombosis venosa profunda concomitante. Los estudios permitieron diagnosticar una trombofilia hereditaria asociada a déficit hereditario de proteína $C$. Palabras clave: sepsis, coagulación intravascular diseminada, trombosis venosa profunda, déficit de proteína $C$.
\end{abstract}

\section{SUMMARY}

Disseminate intravascular coagulation (DIC) is a clinical pathological syndrome associated to several diseases. Sepsis is the most common cause in infants and children. DIC results from the anomalous activation of blood coagulation, widespread formation of thrombi in the microcirculation, and consumption of clotting factors and platelets. Clinical findings are variable; the most common is bleeding, followed by purpura and acral gangrene (purpura fulminans).

We report a patient with sepsis associated-DIC and concurrent deep venous thrombosis. The diagnostic evaluation allowed to discover inherited thrombophilia associated to protein $\mathrm{C}$ deficiency.

Key words: sepsis, disseminate intravascular coagulation, deep venous thrombosis, protein $\mathrm{C}$ deficiency.

http:/ /dx.doi.org/10.5546/aap.2013.e28

a. Terapia Intensiva Pediátrica.

Hospital Provincial de Neuquén

"Dr. Eduardo Castro Rendón".

Correspondencia:

Dr. Mauro Tassin: mtassin@hospitalneuquen.org.ar

Conflicto de intereses: Ninguno que declarar.

Recibido: $10-4-12$

Aceptado: 29-10-12

\section{INTRODUCCIÓN}

Se presenta el caso clínico de un niño con diagnóstico de sepsis, que presenta coagulación intravascular diseminada (CID) con trombosis venosa profunda (TVP) y en quien se diagnostica posteriormente un trastorno de la coagulación hereditario por déficit de proteína $C$.

\section{CASO CLÍNICO}

Un niño de 15 meses es llevado a un hospital del interior de la provincia de Neuquén por un cuadro de fiebre y vómitos aislados, de 48 horas de evolución. Había nacido de embarazo de término con peso adecuado; estuvo internado en Neonatología a los 30 días de vida por sepsis por estreptococo betahemolítico del grupo B, y a los 11 meses por neumonía adquirida en la comunidad, sin aislamiento del germen. Inmunizaciones completas.

A las 12 horas de haber ingresado se agregaron edema en el tercio proximal del muslo, dolor a la palpación e impotencia funcional.

Se realizó un hemograma que mostró: leucocitos $30000 / \mathrm{mm}^{3}$ (cayados $9 \%$; segmentados: $86 \%$ ), PCR+++, sedimento de orina normal, hemocultivos, urocultivo y punción lumbar (citoquímico) normal. Fue derivado al Hospital Provincial de Neuquén.

$\mathrm{Al}$ ingresar en este nosocomio se constató taquicardia $(160 \mathrm{lpm})$, taquipnea (52 pm), tiempo de llenado capilar de 3 segundos, somnolencia y tensión arterial no invasiva de 113/65 mmHg.

El miembro inferior izquierdo se encontraba en posición antálgica, con edema blando e incremento del área comprometida, frío, y dolor generalizado a la palpación del muslo. La diferencia entre la circunferencia de ambos muslos era de 3 $\mathrm{cm}$. Asimismo, se detectó una picadura de insecto en la región inguinal izquierda.

La ecografía de la zona involucrada mostró un discreto engrosamiento y aumento de la ecogenicidad del tejido celular subcutáneo del muslo, con líquido laminar en contacto con la fascia; la cadera era normal. 
Interpretándose el cuadro como sepsis grave, se inició reanimación con cristaloides y dopamina a razón de $10 \mu \mathrm{g} / \mathrm{kg} / \mathrm{min}$. Se realizó un nuevo hemocultivo y se medicó con penicilina y clindamicina.

Fue evaluado por el Servicio de Traumatología y se interpretó el cuadro como fascitis necrosante. Ingresó en el quirófano, donde quedó descartado ese diagnóstico.

Ingresó en Terapia Intensiva Pediátrica, hemodinámicamente estable e intubado, por lo que fue conectado a asistencia ventilatoria mecánica (AVM) y se solicitaron estudios de laboratorio (Tabla 1). La ecografía Doppler del miembro afectado mostró trombosis venosa profunda en las venas femorales comunes, superficiales, cayado de la safena y poplítea.

Se reinterpretó el cuadro como shock séptico más trombosis venosa profunda (TVP) en el contexto de una coagulación intravascular diseminada. Se comenzó la infusión intravenosa de heparina no fraccionada a un ritmo de $10 \mathrm{UI} /$ $\mathrm{kg} / \mathrm{h}$ y se transfundió con concentrado de plaquetas y plasma fresco congelado. Posteriormente requirió el empleo de adrenalina hasta una dosis de $0,2 \mathrm{ug} / \mathrm{kg} / \mathrm{min}$, luego de lo cual se estabilizó, con mediciones de saturación venosa central adecuada y buenos parámetros hemodinámicos. La evolución fue favorable, estuvo 8 días en AVM y 7 días con inotrópicos. En los hemocultivos se aisló estreptococo betahemolítico del grupo A.

Recibió 7 días de tratamiento con heparina no fraccionada y continuó luego con heparina de bajo peso molecular por un lapso de 3 meses. La ecografía Doppler en el momento del alta no mostró cambios. Egresó del hospital a los 18 días.

TABLA 1. Valores de laboratorio al ingresar

\begin{tabular}{lcc}
\hline & Resultado & Valor normal \\
\hline Hematocrito & $22 \%$ & $35-42 \%$ \\
Recuento de plaquetas & $15000 / \mathrm{mm}^{3}$ & $130000-350000 / \mathrm{mm}^{3}$ \\
Tiempo de protrombina & $21 \mathrm{~s}(42 \%)$ & $11-15 \mathrm{~s}$ \\
TTPa & $50,6 \mathrm{~s}$ & $26-40 \mathrm{~s}(70-100 \%)$ \\
Fibrinógeno & $100 \mathrm{mg} / \mathrm{dl}$ & $200-400 \mathrm{mg} / \mathrm{dl}$ \\
Dímero D & $88 \mu \mathrm{g} / \mathrm{dl}$ & Hasta $0,5 \mu \mathrm{g} / \mathrm{dl}$ \\
Proteína C & $7 \%$ & $70-130 \%$ \\
Proteína S & $36 \%$ & $80-120 \%$ \\
Antitrombina III & $38 \%$ & $80-120 \%$ \\
\hline
\end{tabular}

TTPA: tiempo de tromboplastina parcial activado.
En el momento del egreso se realizaron estudios para evaluar la posible presencia de trombofilia:

- VDRL: negativa.

- Inhibidor lúpico: negativo.

- Anticuerpos anticardiolipinas: IgG 93 UPML/ml (+ fuerte), IgM 16 UPML/ml (+).

- Anticuerpos anti-B2 glucoproteína I: IgG 6 U/ml (negativo), IgM $4 \mathrm{U} / \mathrm{ml}$ (negativo).

Los estudios se repitieron a los 2 meses; la proteína C persistía en valores bajos $(28 \%)$, con normalización de la proteína S (70\%), ATIII (128\%) y valores de anticuerpos anticardiolipinas (se descartó un síndrome antifosfolipídico asociado a infecciones).

- Resistencia a la proteína C: 162 segundos (negativo).

- Complemento C3 y C4: normales.

A través de un interrogatorio dirigido se detectó la presencia de un primo de 13 años con accidente cerebrovascular y una tía de 36 años con trombosis venosa profunda que recibía tratamiento anticoagulante. Se estudió la familia y se hallaron valores de proteína $C$ en la madre de $40 \%$ y en la tía de $55 \%$ (VN 70\% a $130 \%$ ).

El paciente continuó en seguimiento por hematología e inmunología con diagnóstico de trombofilia hereditaria por déficit de proteína $C$.

\section{DISCUSIÓN}

Se presenta el caso de un paciente con un cuadro de sepsis con CID y TVP. Dado que la TVP no representa una manifestación frecuente asociada a la CID, se amplía la evaluación diagnóstica para descartar otras causas de trombofilia que pudieran estar asociadas. En la evaluación inicial se detectaron valores muy bajos de proteína $\mathrm{C}$ y anticuerpos anticardiolipinas $\mathrm{G}$ y $\mathrm{M}$ positivas. El seguimiento posterior permitió descartar el diagnóstico de síndrome antifosfolipídico asociado a infecciones, al comprobar la normalización de los anticuerpos, hecho que no ocurrió con los valores de proteína $\mathrm{C}$.

En la fisiopatología de la CID, se produce una liberación de factores procoagulantes como resultado del daño tisular. Estos activan la cascada de la coagulación a través del factor tisular y el factor VII, promoviendo la formación de fibrina en la microcirculación (microangiopatía trombótica) y consumo de plaquetas. El sistema fibrinolítico no puede contrarrestar el depósito sistémico de fibrina, pero sus productos interfieren en la agregación plaquetaria, la polimerización de la fibrina y la actividad de la trombina. Se consumen los factores de la coagulación y los inhibidores de esta. 
Todo este desequilibrio genera, como manifestación clínica, hemorragias y fenómenos trombóticos con lesión de órganos diana. ${ }^{1-3}$

El diagnóstico de CID es clínico y se basa en hallazgos de laboratorio que muestran consumo de plaquetas y factores de la coagulación, incremento en la formación de fibrina y fibrinólisis aumentada. ${ }^{4}$ La plaquetopenia, la prolongación del TP y del TTPa, y la hipofibrinogenemia son frecuentes, pero poco específicos; es más útil la determinación seriada. ${ }^{4}$

El diagnóstico de CID es poco probable sin evidencia de fibrinólisis aumentada con la detección de PDF o Dimera D, estos últimos más específicos. Ambos pueden aumentar en los pacientes con trauma, tromboembolia venosa o cirugía reciente. ${ }^{4,5}$

La clave del tratamiento es resolver el trastorno subyacente que provocó la CID. Si hay hemorragia deben reponerse los déficits específicos con plaquetas, plasma fresco congelado y crioprecipitados. De presentarse manifestaciones trombóticas graves se requiere anticoagulación con heparina no fraccionada continua..$^{6-8}$ Esta fue la conducta terapéutica asumida inicialmente con el paciente, a la que se añadió la administración de PFC (como fuente de AIII; proteínas C y S) y plaquetas (para disminuir el riesgo de sangrados espontáneos).

La proteína $C$ se sintetiza en el hígado (dependiente de la vitamina K) y circula en el torrente sanguíneo como cimógeno. Su forma activa inhibe los factores Va y VIIIa de la coagulación, proceso mediado por la trombina. El déficit de proteína $C$ es de herencia autosómica dominante ${ }^{9}$ y se estima que está presente en el $2 \%$ al $5 \%$ de la población que sufrió algún episodio de tromboembolia. ${ }^{10}$ Tres síndromes clínicos se asociaron con ese déficit: púrpura fulminante neonatal, necrosis cutánea inducida por warfarina y, como en el paciente del caso analizado, tromboembolia venosa. ${ }^{11} \mathrm{El}$ manejo de eventos trombóticos en casos de deficiencia grave de proteína $C$ requiere el reemplazo con concentrados de la misma, mientras se mantiene la anticoagulación (que no difiere de la de cualquier paciente con enfermedad tromboembólica, con los recaudos para prevenir la necrosis cutánea por warfarina). La anticoagulación debe mantenerse entre 3 y 6 meses. ${ }^{12}$ El tratamiento a largo plazo de los pacientes con grave deficiencia de proteína $C$ requiere anticoagulación con o sin regímenes de reemplazo. Mayor controversia existe en los pacientes con episodios únicos de trombosis, en quienes debe sopesarse el riesgo de recurrencia con los riesgos del tratamiento anticoagulante a largo plazo. ${ }^{11-14}$

Numerosas comunicaciones bibliográficas describen las manifestaciones trombóticas en los pacientes con CID ${ }^{1-5}$ Asimismo, desde la publicación de Griffin y cols., en $1982,{ }_{1}^{14}$ numerosas publicaciones muestran la asociación entre el déficit de proteína $\mathrm{C}$ y la trombosis, y en los casos de déficit grave, con la púrpura fulminante y la CID en las primeras etapas de la vida. ${ }^{15,16}$ En el caso presentado, la evaluación y el seguimiento del laboratorio de hemostasia permitieron el diagnóstico de trombofilia hereditaria, con seguimiento y eventual tratamiento a largo plazo.

\section{BIBLIOGRAFÍA}

1. Levi M. Disseminated intravascular coagulation. Crit Care Med 2007;35(9):2191-5.

2. Bick RL. Disseminated intravascular coagulation current concepts of etiology, pathophysiology, diagnosis, and treatment. Hematol Oncol Clin North Am 2003;17(1):149-76.

3. Favaloro EJ. Laboratory testing in disseminated intravascular coagulation. Semin Thromb Hemost 2010;36(4):458-67.

4. Levi M, Toh CH, Thachil J, Watson HG. Guidelines for the diagnosis and management of disseminated intravascular coagulation. Br J Haematol 2009;145(1):24-33.

5. Franchini M, Manzato F. Update on the treatment of disseminated intravascular coagulation. Hematology 2004; 9(2):81-5.

6. Franchini M, Lippi G, Manzato F. Recent acquisitions in the pathophysiology, diagnosis and treatment of disseminated intravascular coagulation. Thromb J 2006;21:4-4.

7. Zeerleder S, Hack CE, Wuillemin WA. Disseminated intravascular coagulation in sepsis. Chest 2005;128(4):2864-75.

8. Clouse LH, Comp PC. The regulation of hemostasis: the protein C system. N Engl J Med 1986;314(20):1298-304.

9. Tait RC, Walker ID, Reitsma PH, Islam SI, et al. Prevalence of protein $\mathrm{C}$ deficiency in the healthy population. Thromb Haemost 1995;73(1):87-93.

10. Martinelli I, Mannucci PM, De Stefano V, Taioli E, et al. Different risks of thrombosis in four coagulation defects associated with inherited thrombophilia: a study of 150 families. Blood 1998;92(7):2353-8.

11. Koster T, Rosendaal FR, Briët E, van der Meer FJ, et al. Protein $C$ deficiency in a controlled series of unselected outpatients: an infrequent but clear risk factor for venous thrombosis (Leiden Thrombophilia Study). Blood 1995;85(10):2756-91.

12. Goldenberg NA, Manco-Johnson MJ. Protein C deficiency. Haemophilia 2008;14(6):1214-21.

13. KnoeblPN. Human protein C concentrates for replacement therapy in congenital and acquired protein $C$ deficiency. Drugs Today (Barc) 2008;44(6):429-41.

14. de Kort EH, Vrancken SL, van Heijst AF, Binkhorst M, et al. Long-term subcutaneous protein $C$ replacement in neonatal severe protein C deficiency. Pediatrics 2011;127(5):e133842.

15. Griffin JH, Evatt B, Zimmerman TS, Kleiss AJ, Wideman C. Deficiency of protein $C$ in congenital thrombotic disease. J Clin Invest 1981; 68: 1370-3. 